\title{
A LETTER FROM THE PRESIDENT
}

\section{To the Members of the American Mathematical Society:}

In the autumn of 1920 a committee under the leadership of Professor E. R. Hedrick inaugurated a campaign to increase the membership of the Society and to secure new subscriptions to our journals. The effort was successful, but we have been surprised to find that over sixty per cent of the mathematicians in our colleges and universities are still not members.

The campaign was undertaken on account of the greatly increased costs of administration, and especially of printing, which have followed the great war. By securing special funds which will not be available in future years the sizes of the Bulletin and Transactions have been kept nearly normal during 1921, but the Society is facing the possibility of serious reductions in 1922 if our resources can not be increased.

For this reason the Council of the Society has authorized the continuation of the campaign for memberships and subscriptions during the years 1921 and 1922. Many of the members of the Society have taken effective interest in the campaign, and their assistance has been greatly appreciated by the membership committee and the officers of the Society. It is possible that others also could help materially if they understood the importance of such assistance during this critical period in the development of our American mathematical school.

I am taking this occasion, therefore, to remind our members of the needs of the Society at the present time, and to urge them to seek opportunities to increase the sizes of our membership and subscription lists. This can be done, for example, by making sure that colleagues who are not members have reasonably considered the desirability of membership in the Society, by subscribing to the Transactions, or by securing subscriptions to the Bulletin and Transactions from your college and city libraries.*

Gilbert A. Bliss,

President of the American Mathematical Society.

\footnotetext{
* See the announcement of special rates for back numbers of our journals on $p$. iii near the back cover of this number.
} 